\title{
Breaking into Merck's CCK Patents: the Starting Point of PNB Vesper Life Science to Design and Develop Cholecystokinin(CCK)-Antagonists as Targeted Chemotherapeutics
}

\author{
Eric Lattmann*1 and Pornthip Lattmann ${ }^{2}$ \\ ${ }^{1}$ School of Life and Health Sciences, Aston University, England \\ ${ }^{2}$ PNB Vesper Life Science PVT, India
}

Received: 眥 March 23, 2018; Published: 制 March 29, 2018

*Corresponding author: Dr Eric Lattmann, Aston School of Pharmacy, Aston University, England

\begin{abstract}
Early anti-cancer research was dominated by the development of alkylating agents, followed by the discovery of a variety of anti-metabolites, which were useful anti-viral agents at the same time. Current anti-cancer drugs are designed towards molecular targets in order to reduce their toxicity and to enhance the selectivity on the cancer cells. Within an increasingly growing number of molecular targets, the cholecystokinin, as a neuro modulator, became an important anti-cancer target, especially when it was shown that cholecystokinin regulates the invasiveness of human pancreatic cancer cell lines via the protein kinase $\mathrm{C}$ pathway. The low potency and the lack of subtype receptor selectivity of those early non-peptide CCK-antagonists, was improved in the following generations of CCK antagonists. These potent and selective antagonists have shown disappointing results in clinical trials due to a poor bioavailability. Initially cholecystokinin was discussed as growth factor, not only in pancreatic cancer, but also for lung, breast, colon and brain cancer, followed by a detailed discussion of over 20 different chemical classes having been developed to date, mainly for the area of neuroscience. Loxiglumide, CI-988, Devazepide, L-365,260 and YM022 are highlighted including in vivo studies and clinical trials. Moreover, CCK antagonists were found useful in the enhancement of the analgesic effects of morphine and the anti-neo plastic effect of cis-platinium. Clinical trials are ongoing. It is concluded that non peptidal cholecystokinin receptor antagonists are modern, non-toxic anti-cancer agents.
\end{abstract}

Abbreviations: GI: Gastrointestinal: Bt2cGMP:Dibutyryl Cyclic Guanosine Mono Phosphate; Bt ${ }_{2}$ cGMP:Dibutyryl Cyclic Guanosine Mono Phosphate; CCK: Cholecystokinin

\section{Introduction}

Several gastrointestinal (GI) hormones, such as gastrin, cholecystokinin, and bombesin, have been reported to affect the development of pancreatic cancer. The receptors for these hormones are found in normal and neo plastic pancreatic cells. Activation of these receptors enhances pancreatic carcinogenesis and promotes the growth of established pancreatic carcinoma either in vitro or in vivo. Studies have shown that these GI hormones may play an inhibitory role in the development of pancreatic cancer. In recent years, increasing emphasis has been placed on the effects of GI hormones on cancer invasion and metastasis. As the transition from non-invasion to the invasive state is the crucial event in cancer development, further investigation of the way in which GI hormones affect the invasion and metastasis of pancreatic cancer may be important for the development of new therapeutic approaches with eventual clinical utility [1].

Cholecystokinin (CCK) is produced by I cells of the duodenal and jejunal mucosa and exists most prominently as an eight aminoacid hormone (CCK-8). CCK has been long been recognized as having an effect on the regulation of pancreatic secretion [2] and of gall bladder contraction [3]. Cholecystokinin has also been found 
in the brain, where it is widely distributed and may therefore have an effect as a neuromodulator or perhaps as a neurotransmitter. CCK is characterized by the $\alpha$-aminated terminus Trp-Met-AspPhe-NH2 aminated sequence. It was initially identified as a 33 amino acid chain [4] and was later synthesized [5]. Subsequent studies have revealed the existence of multiple forms [6,7]. CCK is derived from a primary prepro-CCK polypeptide of 115 residues. After transcription, enzymatic cleavage results in the formation of many different fractions. $\mathrm{CCK}_{58}, \mathrm{CCK}_{39}, \mathrm{CCK}_{33}, \mathrm{CCK}_{22}$, $\mathrm{CCK}_{8 \mathrm{~s}}$ (sulphated), $\mathrm{CCK}_{8 \mathrm{~ns}}$ (non-sulphated), $\mathrm{CCK}_{7}, \mathrm{CCK}_{5}, \mathrm{CCK}_{4}$ all of them demonstrate biochemical activity [8]. The predominant circulating form is a sulphated tyrosine residue at position 7 . It is important to distinguish between the CCK tetra peptide [9] and octapeptide (Sincalide) [10] as shown in Table 1. Both of them have been extensively studied, particularly in relation to food intake regulation, and have brought a great deal of confusion when it came to anxiety and panic. They have differential affinity for CCK receptors $[11,12]$ different distribution in both the periphery and the brain $[13,14]$ and have various effects on behavior.

Table 1: Amino acid sequence of Cholecystokinin and Penta gastrin fragments.

\begin{tabular}{|c|c|}
\hline CCK 8s & Asp-Tyr-[SO3H]-Met-Gly-Trp-Met-Asp-Phe-NH2 \\
\hline CCK 8 & Asp-Tyr-Met-Gly-Trp-Met-Asp-Phe-NH2 \\
\hline CCK 4 & H-Trp-Met-Asp-Phe-NH2 \\
\hline Pentagastrin & Gly-Trp-Met-Asp-Phe-NH2 \\
\hline
\end{tabular}

\section{Cholecystokinin and Cancer}

Cholecystokinin (CCK) plays an important role in the invasiveness and the production of matrix metalloproteinase- 9 (MMP-9) in human pancreatic cancer cell lines. The pathway of the invasiveness may be associated with MMP-9 of those lines regulated by CCK. Two human pancreatic cancer cell lines were treated with CCK-8 alone, CCK-8 and staurosporine, or CCK-8 and indomethacine. The invasiveness and the production of MMP-9 were decreased with staurosporine but not indomethacine. These results suggest that CCK may regulate the invasiveness and the production of MMP9 via protein kinase $C$ in human pancreatic cancer cell lines [15]. Cholecystokinin (CCK) receptors play a role in the development and growth of pancreatic cancers. The expression of mRNA encoding CCK-A and CCK-B receptors in eight human pancreatic tumour cell lines was detected using reverse transcription-polymerase chain reaction (RT-PCR), but not by RNase protection assays. The K-ras gene, which can be activated by G-coupled protein receptors such as CCK receptors, was mutated in codon 12 in five of the cell lines. In addition, Mia PaCa-2 pancreatic cancer cells did not respond to CCK or gastrin in cell proliferation or focal adhesion kinase (FAK) phosphorylation assays. In contrast, mouse NIH3T3 fibroblasts transfected with human CCK-B receptor (NIH3T3CCK-BR) showed increased proliferation and phosphorylation to the peptides [16].
The gut hormone cholecystokinin exerts various actions on the gastrointestinal tract, including the regulation of growth. The hormone has been reported to induce hypertrophy and hyperplasia of the pancreas and to enhance chemically-induced pancreatic carcinogenesis in animals. Stimulation of endogenous cholecystokinin secretion through the induction of deficiency of intra intestinal proteases and bile salts by trypsin-inhibiting nutrients, bile salt-binding drugs or surgical intervention is also capable of stimulating growth and tumor development in the rat. In man, factors suggested to increase the risk of pancreatic cancer, such as a high-fat and high-protein diet or gastrectomy, are known to stimulate plasma cholecystokinin secretion. Receptors for cholecystokinin have been demonstrated on human pancreatic adenocarcinomas, and cholecystokinin has been demonstrated to enhance the growth of xenografted pancreatic cancer and to inhibit growth of gastric and bile duct cancer [17].

\section{From CNS Drugs to New Anticancer Agents}

Gastrointestinal polypeptide hormones regulate growth of various normal gastrointestinal tissues as well as certain visceral cancers [18]. If Cholecystokinin promotes cell growth, CCK antagonists are ideal chemical anti-cancer targets and many scientists have discovered specific peptide and non-peptide antagonists of $\mathrm{CCK}_{\mathrm{B}}$ /gastrin receptors up to date, mainly for the area of neuroscience. As a result of extensive research, a number of new chemical classes have been developed with a high potency and selectivity towards the cholecystokinin receptor subtypes.

\section{Amino Acid Derivatives}

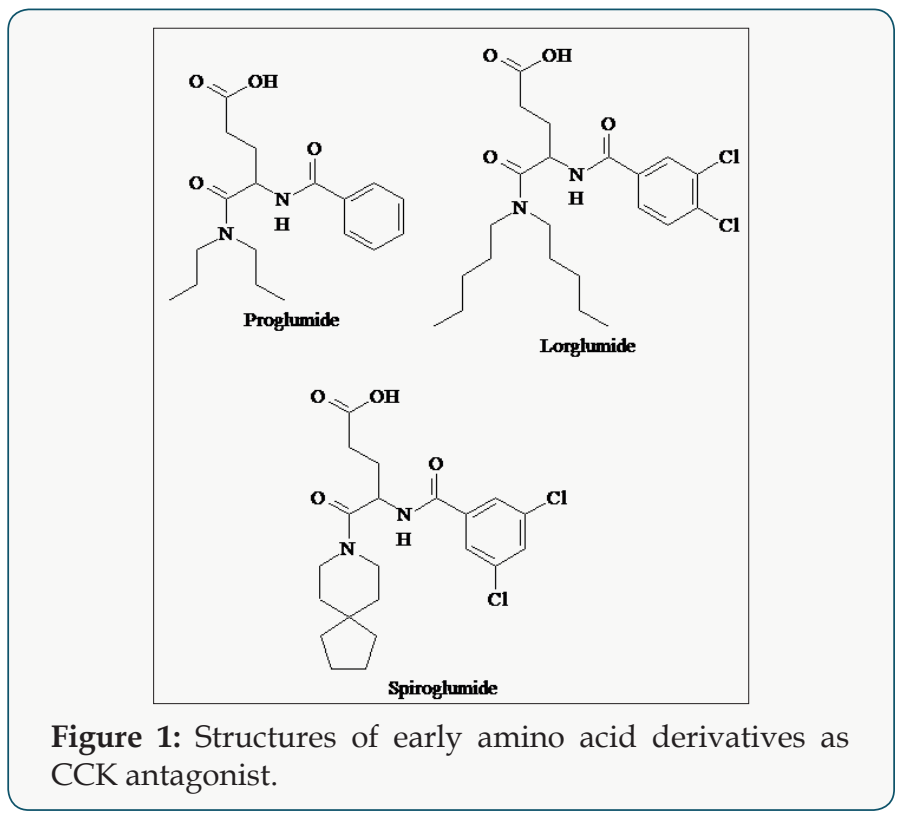

During the 1970's amino acid derivatives (Figure 1) were found to contain anti gastrin activity $[19,20]$. The chemical similarities of gastrin and CCK made it possible for such derivatives to demonstrate CCK antagonist activity. Proglumide, the first putative gastrin 
antagonist clinically available, has long been used in the treatment of peptic ulcers, because of its anti secretory and gastro protective activities. Several studies have subsequently demonstrated that proglumide is also a weak $\mathrm{CCK}_{\mathrm{A}}$ receptor antagonist [21] and despite its low potency, it has been the reference CCK and gastrin antagonist for several years.

Rotta research group produced analogues of proglumide, which showed varying degrees of selectivity for $\mathrm{CCK}_{\mathrm{A}}$ receptors and even suggested possible sub-types of the peripheral receptors. Some derivatives had a higher affinity for pancreatic CCK receptors mediating gallbladder contraction. Lorglumide showed up to a 26-fold increase in potency for blocking CCK-stimulated gallbladder contraction but only a two-fold increase for blocking CCK-stimulated pancreatic amylase secretion [22]. Intravenous administration of Lorglumide [23] antagonized the CCK-induced reduction of gastric emptying in rats, acceleration of intestinal transport in mice, increase in ileal motility in rabbits, gallbladder contraction in guinea pigs and acceleration of gallbladder emptying in mice but showed reduced activity when orally administered. Further structural modifications to Lorglumide resulted in CR2194 (spiroglumide). Spiroglumide exhibited $\mathrm{CCK}_{\mathrm{B}}$ /gastrin antagonist in the micro molar range, with excellent oral bioavailability. However, it has poor selectivity for $\mathrm{CCK}_{\mathrm{B}}$ /gastrin receptor, which raises doubts of its potential therapeutic usefulness. The effect of loxiglumide (LXG) was studied on the invasiveness of two human pancreatic cancer cell lines. Cells were treated with LXG for $24 \mathrm{~h}$, and examined in the invasion assay. Interestingly, the invasiveness of cancer cells and expression of MMP-9 were decreased by LXG in a dose-dependent manner [24].

\section{Loxiglumide and Proglumide as Early Anti-Cancer Agents}

Effects of caerulein (CCK), 5-FU and loxiglumide (CR1505) were studied on the growth of human pancreatic cancer cell line, KP-1 $\mathrm{N}$, in vitro. And effects of UFT and CR 1505 were also studied on liver metastasis in nude mice. The growth of KP-1 $\mathrm{N}$ was stimulated approximately $40 \%$ by addition of $10(-10) \mathrm{M}$ of CCK in vitro. CR1505 antagonized the action of CCK, that is, the $40 \%$ growth rate increase was suppressed by addition of $25 \mu \mathrm{M}$ of CR1505. Moreover, the growth rate of the cells dose-dependently decreased by the addition of CR1505. 5-FU also dose-dependently inhibited the growth of KP-1 $\mathrm{N}$ in culture. 5-FU additionally decreased the growth rate of KP-1 N in combination with CR1505. A number of metastatic nodules were found in the liver of nude mice a month after injections of KP-1 N cells into the spleen CR1505 suppressed the liver metastasis in nude mice [25]. Another study has shown that Lorglumide $(3 \times 10(-5) \mathrm{mol} / \mathrm{l})$ also reduced the basal growth to $30 \%$ of control, which was reversed to $78 \%$ by $10(-5) \mathrm{mol} / \mathrm{l}$ gastrin. Here, Proglumide had no effect on the basal growth of MKN45G [26]. The growth-regulating effects of penta gastrin, gastrin and the gastrin-receptor antagonist proglumide were investigated in three established cell lines derived from human colorectal carcinomas in vitro and after transplantation into nude mice. In vitro a significant increase of cell growth in the SW 403 cell line incubated with penta gastrin or gastrin was observed. In the Lovo cell line this effect was only detected after synchronization of cell growth. Penta gastrin and gastrin had no effect on the growth of the Ls $174 \mathrm{~T}$ cell line. Proglumide reduced cell proliferation in all these three cell lines as well as in the L929S cell line derived from fibroblasts, which served as control. After transplantation into nude mice all tumor cell lines increased, Lovo and Ls $174 \mathrm{~T}$ as undifferentiated tumor, SW 403 as differentiated. Penta gastrin increased and proglumide decreased growth in SW 403 tumors [17].

Further, the effects of loxiglumide (CR1505) on the growth of human pancreatic cancer were studied. Human gastrointestinal cancer xenografted tumors (one esophageal, one gastric, two colorectal, two biliary tract, and two pancreatic cancers) were transplanted into nude mice. The mice were given CR1505 at 250 $\mathrm{mg} / \mathrm{kg}$ daily for 14 days, either subcutaneously or intra gastrically, and the tumor volumes before and after treatment were compared. CR1505 inhibited the growth of the two pancreatic cancer lines, but did not inhibit the growth of the other lines. CR1505 also inhibited in vitro DNA synthesis in the two pancreatic cancer lines at lower concentrations than in the other lines. The effect of CR1505 was inhibited by oral administration of the trypsin-inhibitor, camostate (FOY-305), in both pancreatic cancer lines. These results suggest that CR1505 may specifically inhibit the growth of human pancreatic cancers [27]. The effects of cholecystokinin (CCK) and loxiglumide (CR-1505) were investigated on four freshly separated and six xenografted human pancreatic cancers [28]. The level of DNA synthesis in only one of five tested pancreatic cancers was enhanced by CCK at concentrations of 0.01-10 nM, while in the other four cancers the DNA synthesis was not affected. The levels of DNA, RNA, and protein synthesis (by 3H-thymidine, $3 \mathrm{H}$-uridine, and $3 \mathrm{H}$-leucine incorporation tests, respectively) in all the tested cancers were dose-dependently inhibited by loxiglumide at concentrations of 20-2000 $\mu \mathrm{M}$, and the $\mathrm{IC}_{50}$ of loxiglumide for DNA synthesis in pancreatic cancers was $156+/-80 \mu \mathrm{M}$ (means +/- SD). The in vivo effect of loxiglumide was assessed using a xenografted line (PC-HN) transplanted in nude mice. The in vivo 50\% lethal dose of loxiglumide for nude mice was about $500 \mathrm{mg} / \mathrm{kg}$. Death was caused by respiratory failure due to severe congestion of the lung after the administration of a large dose of loxiglumide. The growth of a PC-HN transplanted in the nude mice was significantly inhibited by subcutaneous loxiglumide at $250 \mathrm{mg} / \mathrm{kg}$, twice a day for 28 days, which did not cause death [29].

\section{Clinical Trials of Loxiglumide}

The effects and safety of loxiglumide on advanced pancreatic cancer were investigated in humans. A perspective, controlled 
(2.4 g/day vs. placebo), randomized, double-blind, parallel-group study was performed in 64 patients affected by non-resectable histologically diagnosed pancreatic cancer. The patients were stratified according to sex and stage (A, T3/N0-N1/M0; B, T1T2-T3/N0-N1/M1; C, relapse after surgical exeresis). Tumor size (by computed tomography scan) and mortality rate were evaluated as efficacy criteria. Clinical symptoms and physical signs, laboratory tests, and adverse reactions were checked every 6 weeks as efficacy/tolerability criteria. Forty-two male and twentytwo female patients were considered. A homogeneous distribution of the patients was demonstrated in the two treatment groups. Group C was not statistically evaluated for survival and tumor evolution because of its small number. Three patients dropped out for causes not related to the therapy. No toxic reactions to the drug were reported. Tumor size monitoring within groups A and $B$ demonstrated a similar increase in both the loxiglumide and the placebo group. Survival in group A was higher than in group B ( $p=$ 0.0003). In group $B$, survival was lower in females $(F)$ than in males (M) $(\mathrm{F}=61.00+/-6.47$ days, $\mathrm{M}=140.44+/-22.15$ days; $\mathrm{p}=0.012)$, while survival by sex was similar in group A and in global analysis. Survival by treatment was similar for groups A and B. Survival by surgery was higher $(p=0.049$ ) for surgical palliation than for non-operated patients. The tumor grade affected survival but it did not vary by therapy. In conclusion, sure efficacy of loxiglumide in advanced pancreatic cancer was not demonstrated by our results. In consideration of its documented tumor growth inhibiting action, we suggest that loxiglumide be tested for recurrence prevention after resective surgery [30].

\section{Cyclic Nucleotide Derivatives}

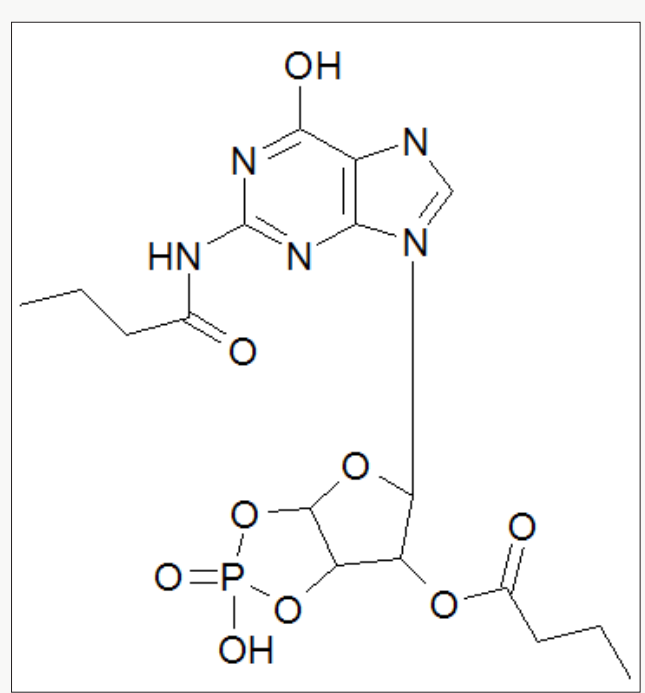

Figure 2: Structure of $\left(\mathrm{Bt}_{2} \mathrm{cGMP}\right)$.

Dibutyryl cyclic guanosine mono phosphate ( $\mathrm{Bt}_{2} \mathrm{cGMP}$ ) was the first competitive antagonist of CCK-mediated action to be discovered [31] Figure 2. It was found to cause both reversible and selective inhibition of CCK-stimulated amylase secretion from rat pancreatic cells. Subsequently it was found to block the effects of CCK at many peripheral sites. However, $\mathrm{Bt}_{2} \mathrm{cGMP}$ failed to inhibit CCK binding in mouse cerebral cortex.

\section{Tryptophan Dipeptoid Derivatives}

A research group at Parke-Davis [32,33] examined the activity of CCK-30-33 fragments, in binding experiments on $\mathrm{CCK}_{\mathrm{B}} /$ gastrin receptors. This led to the development of C1-988 (Figure 3), which exhibited 1600-fold selectivity for $\mathrm{CCK}_{\mathrm{B}}$ over $\mathrm{CCK}_{\mathrm{A}}$ receptors. Structural C-terminal modifications led to alternative compounds, which demonstrated sub-nano molar affinity for $\mathrm{CCK}_{\mathrm{B}}$ /gastrin receptors. Compound (1) displayed high affinity $\left(\mathrm{IC}_{50}=0.3 \mathrm{nM}\right)$. Further structural modifications, to optimize the substitution on the phenyl ring of (1) led to the analogue (2). This showed exceptionally high affinity for $\mathrm{CCK}_{\mathrm{B}}$ /gastrin receptors, $\left(\mathrm{IC}_{50}=0.08\right.$ $\mathrm{nM}$ ) and was 940 times more selective over the CCKA receptor. However, due to the high molecular weight and the dipeptoid structure these derivatives have a low bioavailability, and therefore, are not suitable drugs for oral therapy.

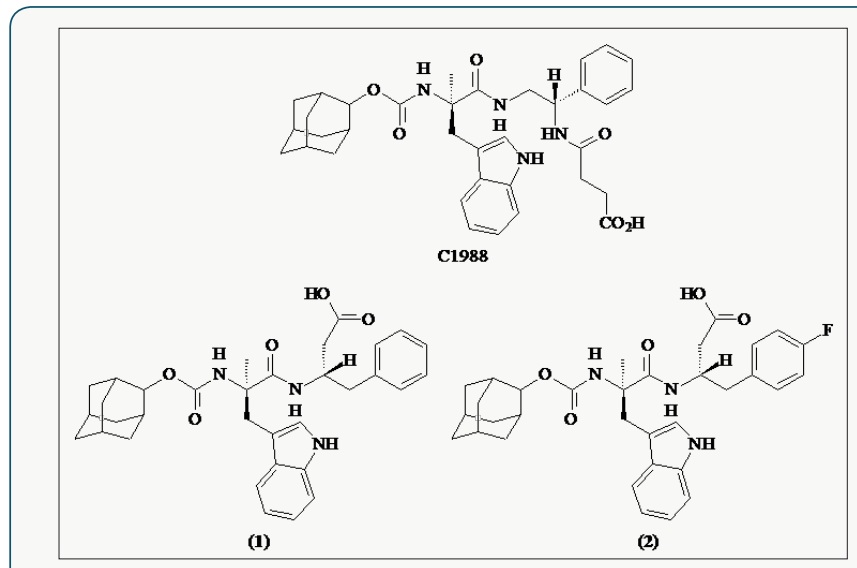

Figure 3: Tryptophan dipeptoid $\mathrm{CCK}_{\mathrm{B}}$ antagonists.

\section{Evaluation of CI-988 as Anti-Cancer Agent}

The effect of a new, potent and selective $\mathrm{CCK}_{\mathrm{B}}$ receptor antagonist, CI-988 on the growth of LoVo, a human colon cancer cell line both in vitro and in vivo was instigated. Basal growth of LoVo in vitro was inhibited by up to $58.93+/-7.30 \%$ with concentrations of CI-988 as low as $1 \mathrm{X} 10(-11) \mathrm{mol} / \mathrm{L}$ whereas the addition of gastrin (G17) at $0.5 \mathrm{nmol} / \mathrm{L}$ had no effect [34]. In further studies [35], the dose-response relationship of CI-988 on the growth of LoVo, a human colon cancer cell line, was studied in vivo. LoVo was grown for 10 days in nude mice that were then treated with CI-988 at 1, 5, 10,25 and $50 \mathrm{mg} / \mathrm{kg}$ per day orally for 20 days. CI-988 significantly inhibited the growth of xenografts at all concentrations except the highest concentration of $50 \mathrm{mg} / \mathrm{kg}$ per day ( $<<0.00001$; ANOVA). The largest inhibitory activity was caused by the $10 \mathrm{mg} / \mathrm{kg}$ per day dose, causing a 47\% inhibition at day 29 (P = 0.00003: NewmanKeul's test). 


\section{Peptides}

The first CCK related peptide found to demonstrate CCK receptor agonist was CCK-27-32- $\mathrm{NH}_{2}$. This inhibited CCK-induced pancreatic enzyme secretion. Clark [36] claimed the C-terminal phenylalanine is essential for intrinsic activity but not for binding. The L-tryptophan residue is important also for binding to both central and peripheral CCK receptors. In another study [37], a synthetic peptide derivative of CCK-7, t-butyloxycarbonyl-Tyr(SO3)-Met-Gly-D-Try-Nle-Asp2-phenylethyl ester inhibited binding of labelled CCK-9 to both pancreatic acini and cerebral cortical membranes, in addition to blocking agonist-stimulated amylase secretion. The lack of oral bioavailability of these peptide CCK antagonists severely restricts their potential therapeutic use.

\section{Pyrazolidinones}

Scientists from Lilly identified, through a bulk random screening technology, a series of functionalized pyrazolidinone derivatives. Structure-activity relationship studies [38] led to the identification of compounds such as LY26269 (Figure 4 \& Table2), with binding affinities of $31 \mathrm{nM}$ and $11,600 \mathrm{nM}$ for the ССКВ \& CCKA receptors, respectively. It showed more than 350-fold selectivity for CCKB receptors [39]. As observed with the other series, binding affinity \& selectivity for the receptor subtypes was dependent on the absolute stereochemistry of the chiral centres in the molecule. LY288513 having 4S, 5R stereochemistry at the twophenyl centres retains most of the binding affinity of the racemate, whereas the corresponding enantiomer LY288512 is significantly less potent. Stereo-dependent interactions with the CCK receptors were further substantiated within the same series of compounds having CCKA receptor selectivity. Therefore the racemic thiourea analogue had binding affinities of $880 \mathrm{nM}$ and $42 \mathrm{nM}$ for the CCKB \& CCKA receptors, respectively. The CCKA binding affinity was improved for the enantiomer, having $4 \mathrm{R}$, $5 \mathrm{~S}$ configuration at the two-phenyl centres. However, the corresponding enantiomer was significantly less active and showed modest CCKB selectivity. Further development of compound has been discontinued due to adverse effects in preclinical toxicological studies [40].

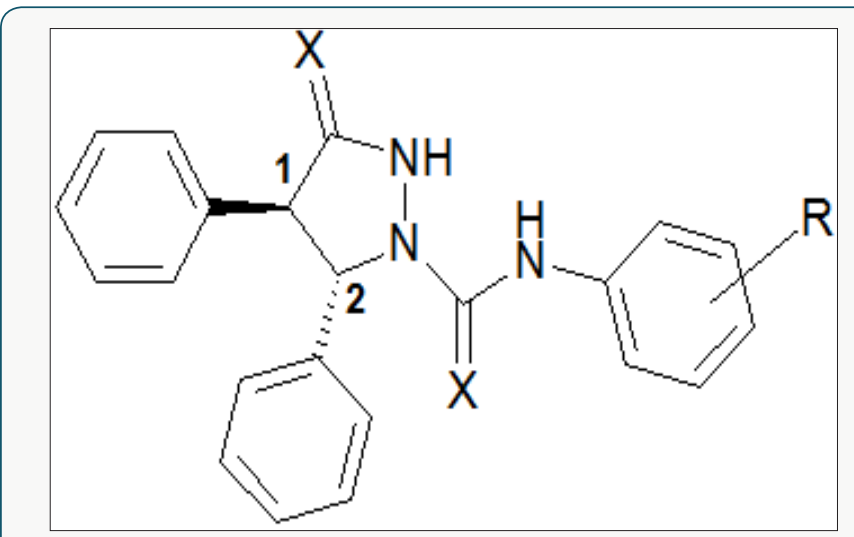

Figure 4: Pyrazolidinone derivatives.
Table 2.

\begin{tabular}{|c|c|c|c|c|c|c|}
\hline Compound & $\mathbf{X}$ & $\mathbf{R}$ & $\mathbf{1}$ & $\mathbf{2}$ & CCKA & CCKB \\
\hline & & & & & IC50 & [nM] \\
\hline LY262691 & O & $\mathrm{p}-\mathrm{Br}$ & $\mathrm{R} / \mathrm{S}$ & $\mathrm{R} / \mathrm{S}$ & 11600 & 31 \\
\hline LY288512 & $\mathrm{O}$ & $\mathrm{p}-\mathrm{Br}$ & $\mathrm{R}$ & $\mathrm{S}$ & 10400 & 370 \\
\hline LY288513 & $\mathrm{O}$ & $\mathrm{p}-\mathrm{Br}$ & $\mathrm{S}$ & $\mathrm{R}$ & 20500 & 19 \\
\hline $\mathrm{D}$ & $\mathrm{S}$ & $\begin{array}{c}\mathrm{m}-\mathrm{CF} 3, \\
\mathrm{p}-\mathrm{Cl}\end{array}$ & $\mathrm{R} / \mathrm{S}$ & $\mathrm{R} / \mathrm{S}$ & 42 & 880 \\
\hline $\mathrm{E}$ & $\mathrm{S}$ & $\begin{array}{c}\mathrm{m}-\mathrm{CF} 3, \\
\mathrm{p}-\mathrm{Cl}\end{array}$ & $\mathrm{R}$ & $\mathrm{S}$ & 17 & 1900 \\
\hline $\mathrm{F}$ & $\mathrm{S}$ & $\begin{array}{c}\mathrm{m}-\mathrm{CF} 3, \\
\mathrm{p}-\mathrm{Cl}\end{array}$ & $\mathrm{S}$ & $\mathrm{R}$ & 810 & 550 \\
\hline
\end{tabular}

\section{Ureidoacetamides}

Developed by Rhone-Poulenc, these non peptide ureidoacetamides are potent and selective ligands for CCKB/ gastrin receptors. Compound RP69758 demonstrated nano molar activity for CCKB/gastrin receptors, whilst exhibiting 100-1000 fold selectivity for $\mathrm{CCKB} /$ gastrin receptors over CCKA receptors [41] (Figure 5).

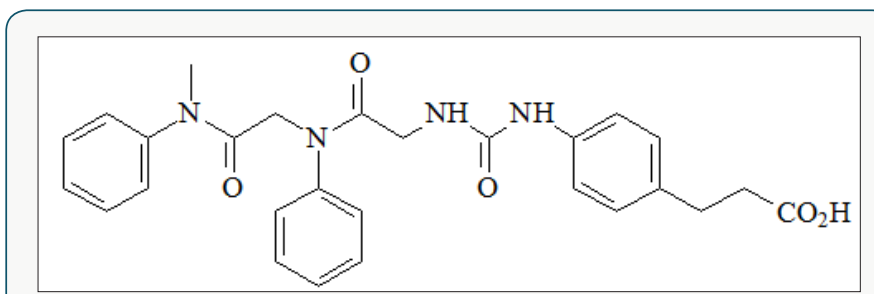

Figure 5: Ureidoacetamide derivative RP69758.

\section{Ureidophenoxyacetanilides}

In order to avoid adverse effects derived from CCKA receptor antagonist activity with gastrin/CCKB receptor antagonists (exemplified for Proglumide) scientists from Japan [42] have developed a series of phenoxyacetanilide derivatives, which were linked with the ureido-phenyl moiety. The most active compound of this series is DZ-3514, which demonstrated nano molar activity for CCKB/gastrin receptors ( $0.8 \mathrm{nM})$ with $250-500$ fold selectivity over CCKA receptors (Figure 6)

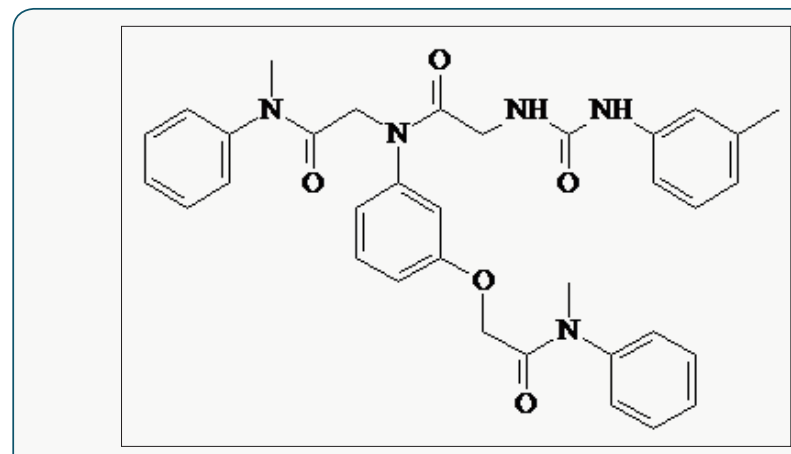

Figure 6: Ureidophenoxy acetanilide derivative DZ-3514. 


\section{Ureidomethylcarbamoylphenylketones}

A series of ureido-methylcarbamoyl-phenylketones [43] has been developed as selective CCKB receptor antagonists. This series of compounds exemplified by the urea, was derived by cleavage of the $\mathrm{C}-3 / \mathrm{N}-4$ bond of the 1,4-benzodiazepine L-365,260 (3). The highlight of this series was S-0509 (4), which had 120-fold selectivity for CCKB receptors over CCKA (Figure 7).

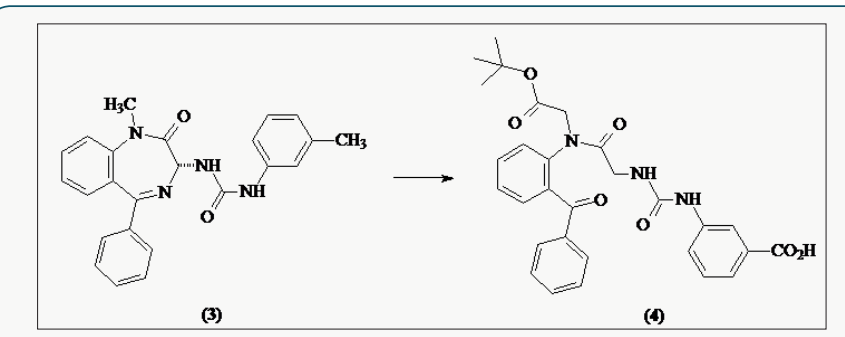

Figure 7: Structures of 3-ureido-1,4-benzodiazepine derivative L-365,260 (3) and Ureidomethylcarbamoylphenylketones derivative S-0509 (4).

\section{Dibenzobicyclo [2.2.2] Octane and Bicyclic Hetero Aromatic Derivatives}

Based on the dibenzobicyclo [2.2.2] octane skeleton (Figure 8), the James Black foundation [44] synthesized potent and selective $\mathrm{CCKB} /$ gastrin antagonist. The most potent compound was (5). Given intravenously at the dose of $0.025 \mu \mathrm{m} / \mathrm{kg}$, it gave a peak inhibition of 79\% of GAS observed for a sub maximal infusion of penta gastrin Therefore it was at least 40 times more potent than L-365.260. Compound (6), a 5,6-disubstituted-indole derivative was the most potent compound of this new series. It totally inhibited (97\%) penta gastrin-stimulated GAS in the rat, when administered intravenously at the dose of $0.025 \mu \mathrm{m} / \mathrm{kg}$ and exhibited a comparable activity in the dog assay.

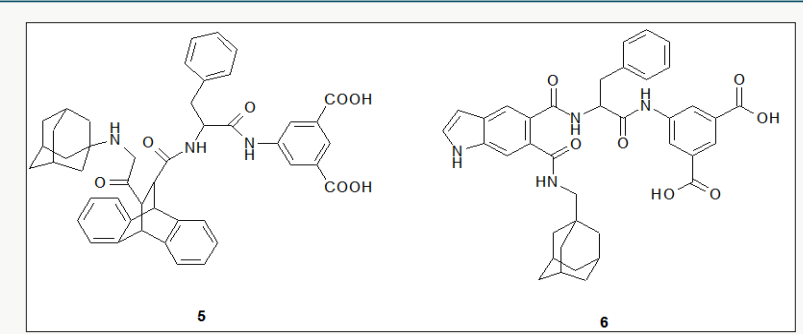

Figure 8: Structures of selected dibenzobicyclo [2.2.2] octane (5) and bicyclic hetero aromatic (6) CCKB antagonists.

Recently the James Black Foundation has described a novel series of gastrin and CCK ligands based on a pyrole or imidazole ring system [45]. The best 2,4,6-trisubstituted imidazole-based compounds displayed an IC50 of $2.95 \mathrm{nM}$, but with no in vivo data is reported yet.

\section{Benzodiazepine Derivatives}

However, benzodiazepines were very weak in displacing CCK in mouse brain (IC50 = $10 \mu \mathrm{M})$ [46]. In a study from Japan anthramycin
[47], a benzodiazepine derivative, was reported to be a potent antagonists of CCK in mice. Anthramycin reversed CCK-8 induced satiety and was shown to displace [125I] CCK-8 binding in different brain regions, especially in the cortex. Further investigations are underway to elucidate the pharmacological potential of this compound (Figure 9). The discovery of Asperlicin was historically important, because it initiated the discovery programmes leading to potent and specific CCKA and CCKB receptor antagonists. This naturally occurring benzodiazepine derivative was isolated from the fungus Aspergillus alliaceus. Asperlicin showed selectivity for CCKA receptors and at the time of its discovery was the most potent non peptide CCK antagonist known with an IC50 of $1.4 \mu \mathrm{M}$ (Figure $10)$.

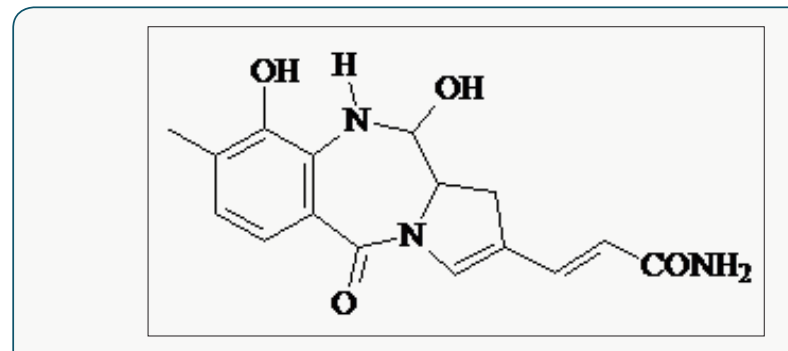

Figure 9: Structure of the natural 1,4-benzodiazepine derivative Anthramycin.

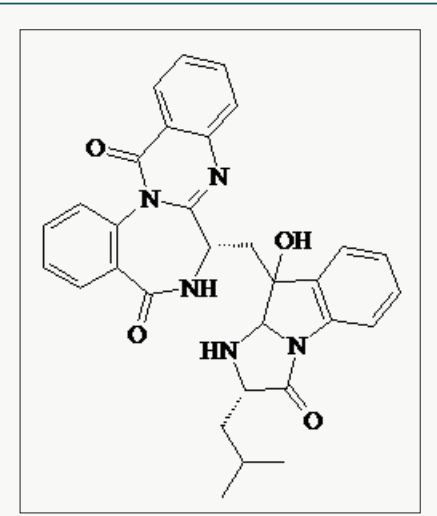

Figure 10: Structure of the natural 1,4-benzodiazepine derivative Asperlicin.

Asperlicin represented a major advance in the development of CCK receptor antagonists. It demonstrated 300-400 times more affinity for pancreatic and gallbladder CCK receptors than proglumide. However, this compound demonstrated scare stability and poor oral bioavailability [48]. By combining the elements of Asperlicin, L-364, 286 was the first successful synthetic analogue, in which the diazepam-like structure is linked with a 3-amido group (Figure 11). New efforts to optimise the CCKA antagonist activity of these benzodiazepine derivatives led to devazepide (MK-329, formerly L-364,718) an extremely potent and orally active CCKA antagonist (IC50 $=0.1 \mathrm{nM}$ inhibition of $125 \mathrm{I}-\mathrm{CCK}-8$ rat pancreas binding). This compound had a more than 1000-fold selectivity for the CCKA receptor and a longer lasting efficacy (Figure 12). 


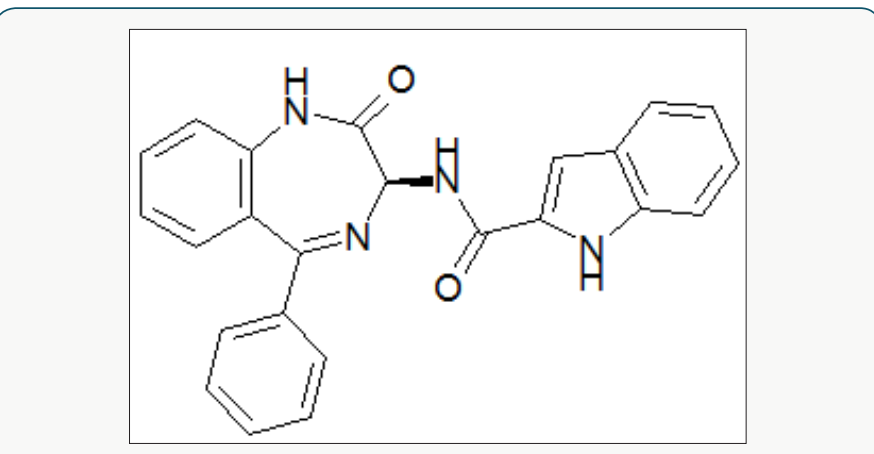

Figure 11: 3-Amido-1,4-benzodiazepine derivative L-364, 286.

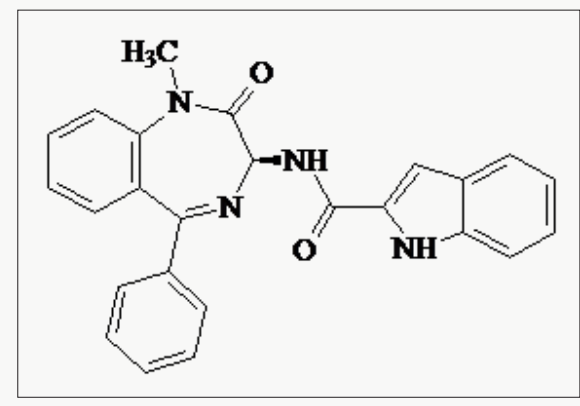

Figure 12: 3-Amido-1,4-benzodiazepine derivative L-364, 718 / MK-329 / Devazepide.

Devazepide possessed a potent CCKA blocking activity in different tissues $[49,50]$. The pancreatic amylase secretion was antagonised with a 2,000,000 times higher potency than proglumide. Devazepide has been claimed [51] to be a selective antagonist inhibiting the effects of CCK-8 (Sincalide) on food intake. In contrast, when CCK-8, was secreted from the gastric mucosa, the release of both bile from the gallbladder, and the release of digestive enzymes from the pancreas were stimulated [52]. Devazepide was a key tool in the autoradiographical demonstration of the presence of CCKA receptors in the various regions of the brain [53]. During the extensive development of L-364, 718 it was noted that some analogues lost their selectivity for CCKA.

\section{Devazepide in the Treatment of Cancer}

Devazepide (L-364718) inhibited in vitro the proliferation of cells and induced morphologic changes in the mucous-secreting, autonomously proliferating human cancer colon cell line (HT29S-B6). Addition of devazepide $(10 \mu \mathrm{M})$ for at least 3 days in the exponential phase of growth enhanced the baseline production of gastric M1 mucins 2-3-fold and that of carcinoembryonic antigens 5 -fold. Moreover, Devazepide induced an increase in the amount of the MUC-5AC mRNA expressed by HT29-S-B6 cells. The increase in mucin secretion, induced by Devazepide, was persistent after removal and independent of the presence of serum [54]. MK-329 inhibited the growth of CCK receptor-positive human pancreatic cancer in athymic mice. Based on these activities and the ability of MK-329 to transiently increase food intake and to enhance morphine analgesia in murine models, an open trial [55] of MK-329 was conducted in 18 patients with advanced pancreatic cancer in whom the CCK receptor status of the tumors was unknown. Tumor response, pain control, and nutritional parameters (hunger rating, caloric intake, body weight, and anthropometrics) were serially assessed. The results of the study failed to demonstrate any impact of MK-329 on tumor progression, pain, or nutrition. Toxicity was mild and limited to nausea, vomiting, diarrhea, and abdominal cramps, with 17 of 18 patients able to tolerate treatment.

\section{Ureidobenzodiazepine Derivatives}

When the 3-amido linkage was replaced with a benzamido urea, the CCKA affinity decreased and the CCKB affinity increased substantially. The most interesting compound developed by Merck scientists [56] was L-365,260. L-365, 260 [57] showed a high affinity for CCKB receptors in rats, mice and in humans. L-364, 718 was reported to have a 125 fold greater affinity for pancreatic CCKA receptors, than for gastrin receptors. L-365,260 has shown only an 80 fold grater affinity for gastrin/CCKB receptors than for pancreatic CCKA. Both L-364,718 and L-365, 260 (Figure 13) were investigated [58] whether the satiety response to CCK is mediated by CCKA or CCKB receptors. L-365, 260 was reported to be 100 times more potent than devazepide in increasing feeding frequency and preventing satiated rats. The conclusion from the study was that endogenous CCK causes satiety by interaction with CCKB receptors in the brain. The high affinity CCKB-selective urea L-365,260 and related analogues is dependent upon the stereochemistry at C-3 position of the benzodiazepine ring, the (3S)-enantiomer generally being CCKA selective and the (3R)-isomer CCKB selective. L-365, 260 shows high affinity for CCKB receptors in rats, mice and in humans. Although L-365,260 represents a benzodiazepine structure, it has no affinity to GABA-A receptors and does not induce tolerance and withdrawal in animal models. During phase 1 clinical trials it was found that L-365,260 had a limited oral bioavailability due to its low aqueous solubility and bio-distribution studies in mice [59] and it has shown very low brain uptakes $(<0.8 \%$ dose/gram $)$ after intravenous injections.

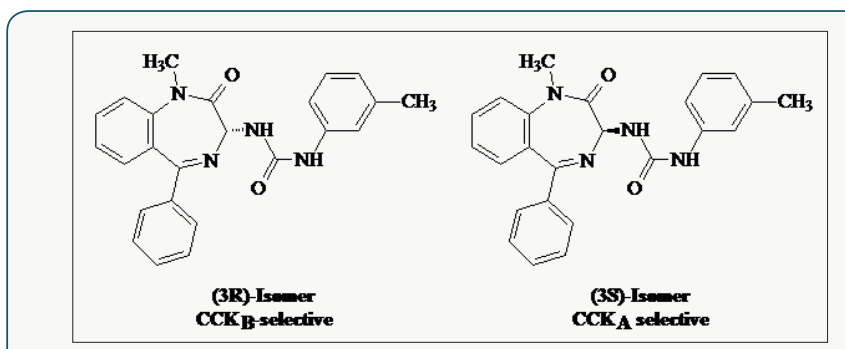

Figure 13: Isomers of 3-ureido-1,4-benzodiazepine derivative L-365, 260.

\section{L-365,260 and its Role in Cancer}

The cell line LN 36 responded in vitro [60] with an increased cell number to stimulation by gastrin-17 and decreased cell number to inhibition by the CCK-B receptor antagonist L-365,260. Specific 
cholecystokinin (CCK) receptor and gastrin receptor antagonists were used to assess what role, if any, these receptors have in autocrine cell growth. Although the cholecystokinin receptor antagonist, L-364,718, inhibited cell proliferation in a broad spectrum of cell lines, the gastrin antagonist, L-365,260, had no effect on cell proliferation. In addition neither added gastrin 17 , nor sulfated cholecystokinin 8 , could reverse the inhibitory action of L-364,718. It is proposed that L-364,718 inhibits cell proliferation independently of classical gastrin/CCK receptors [61]. One of the most potent and selective CCKB receptor ligand is L-708,474 [62]. L-708,474 (Figure 14) displayed a thirty-fold higher affinity than $\mathrm{L}-365,260$ (IC50 $=8.5 \mathrm{nM}$ ) at the CCKB receptor and was found markedly more selective for CCKB receptors over CCKA $(6,500$ fold v. 87-fold). The enhanced binding affinities of the 5-cyclohexyl benzodiazepines demonstrated the importance of the size of the lipophilic substituent at the $\mathrm{C}-5$ position of the benzodiazepine template. L-708,474 (IC50 $=0.28 \mathrm{nM}$ ) was an exceptionally high affinity ligand at the CCKB receptor. L-708,474 is considerably more potent than either the cyclopentyl (IC50 = $16 \mathrm{nM}$ ) or the cyclobutyl (IC50 $=29.9 \mathrm{nM}$ ) analogues. It has shown an increased lipophilicity in comparison to L-365,260, enhanced potency and selectivity for the CCKB receptor, but a decreased bioavailability.

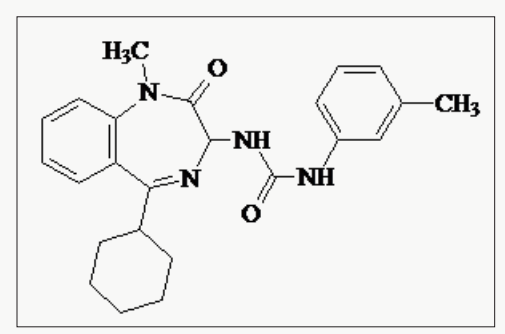

Figure 14: 3-Ureido-1,4-benzodiazepine derivative L-708,474.

Based on Merck's phase 1 trials with L-365,260 a second generation of CCKB/gastrin receptor antagonists was developed. The chemists at Merck hoped to increase the oral bioavailability of the newly synthesized compounds by introducing groups with water-solubilizing properties. One of the compounds with an increased bioavailability [63,64], L-740,093, containing a basic amidine structure, was found to be extremely potent. L-740,093 (Figure 15) showed a one hundred times fold improved water solubility as $\mathrm{HCl}$ salt compared to L-365,260. L-740,093 displayed an IC50 of $0.1 \mathrm{nM}$ for the CCKB receptor and had a CCKA/CCKB ratio of approximately 16000 . Thus L-740,093 seems to be suitable for oral treatment in humans. Another approach to increase the water solubility of L-365,260 in order to achieve good levels of oral bioavailability, was successfully performed by incorporating acidic solubilising groups into the 3-phenyl ring of the acyl-urea moiety [65]. The C5-cyclohexyl derivatives incorporating amino-tetrazole group $(\mathrm{L}-737,425)$ was the most potent and selective (CCKA/CCKB $=37000$ ) antagonists so far reported for CCK-B/gastrin receptors (Figure 16). However, the preparation of this compound includes a synthetic complexity. A novel series of 1-aroylmethyl analogues of L-365,260 was prepared and evaluated for activity as CCKB/gastrin receptor antagonist by the Yamanouchi group [66]. YM022 [67,68] has shown to be a significantly more potent antagonists of penta gastrin than L-365,260. YM022 (Figure 17) exhibited a very high $\mathrm{CCKB} /$ gastrin receptor affinity $(\mathrm{IC} 50=0.11 \mathrm{nM})$ and a CCKA/CCKB ratio about 1300 [69]. YM022 showed, compared to L-365,260, a better bioavailability and is a compromise between the lipophilicity and selectivity for the CCKB receptor. However, the improvement in the obtained potency did not compensate the increase in synthetic complexity.
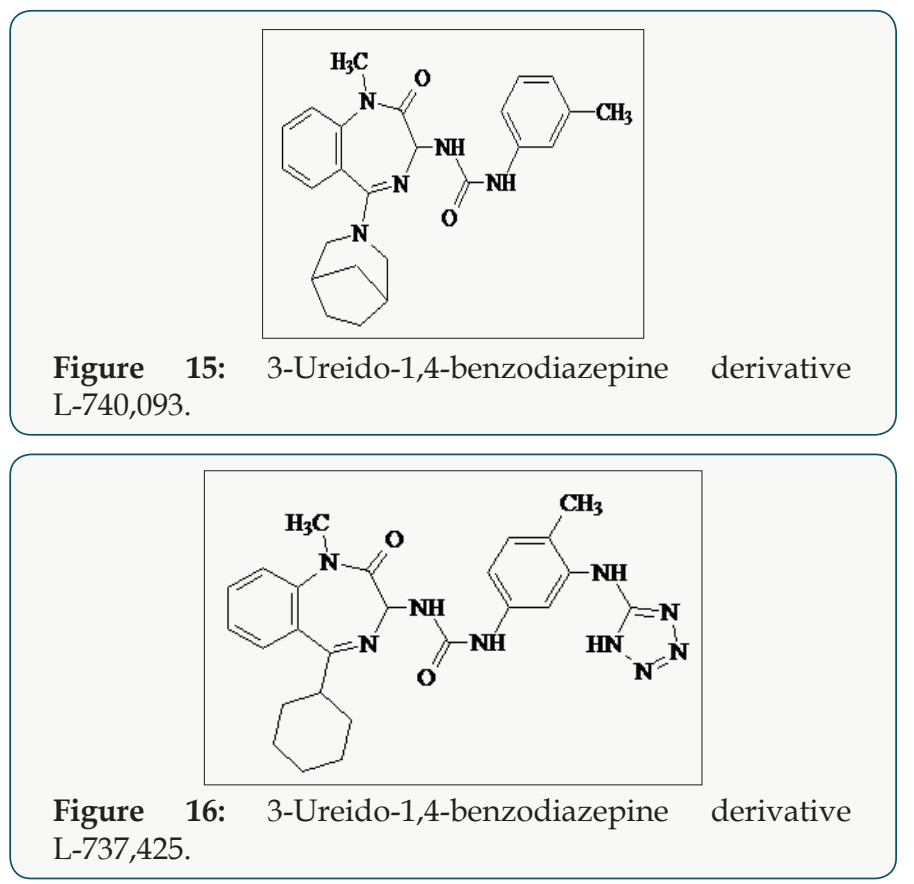

L-737,425.

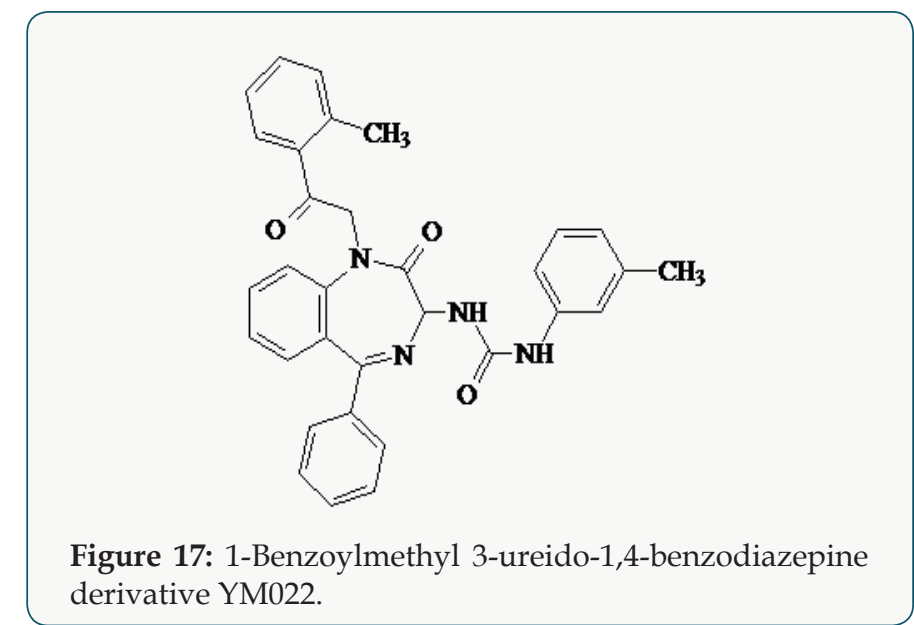

The anti proliferative potency of YM022 was evaluated by using $\mathrm{N}$-hCCKBR cells. YM022 had the most potent activities in competing with [125I] CCK-8 or [125I] gastrin I binding, inhibition of CCK-8or gastrin I-induced phosphoinositide hydrolysis and increasing cytoplasmic free calcium. Interestingly, a potent antagonist for rat CCK-B/gastrin receptors did not have such activities in N-hCCKBR 
cells. YM022 inhibited the CCK-8- or gastrin I-induced [methyl-3H] thymidine incorporation of $\mathrm{N}$-hCCKBR cells in a dose-dependent manner. In the absence of exogenous peptide ligands, YM022 also inhibited the proliferation of several human cancer cell lines expressing the genes for both gastrin and its receptor. These results suggest that YM022 could intervene in the autocrine stimulation of human tumor cell lines through CCK-B/gastrin receptors. N-hCCKBR cells are an excellent tool to screen for novel human CCK-B/gastrin receptor antagonists possessing anti proliferative activity for human cancer cells [70]. Scientists from Pfizer [71] modified the benzodiazepine nucleus of L-365, 260 into a benzazepin-2-one moiety. These compounds demonstrated typical subnanomolar $\mathrm{CCKB} /$ gastrin receptors affinity (IC50 $=0.48 \mathrm{nM}$ ) and have a CCKA/ CCKB ratio of 350 (Figure 18 \& Table 3). Compound 7 (CP212452) potently inhibited penta gastrin induced GAS, with an ED50 of 0.8 $\mathrm{mg} / \mathrm{kg}$ compared to $1.5 \mathrm{mg} / \mathrm{kg}$ subcutaneously for L-365, 260. Despite its potent and selective CCKB/gastrin receptor affinity, it has a poor oral bioavailability due to its low water solubility. The more water-soluble potassium salt of the carboxylic acid derivative CP-310,713 (8) was identified and had improved aqueous solubility and in vivo efficacy (ED50 $=0.03 \mathrm{mg} / \mathrm{kg}$ s.c in the penta gastrin induced GAS model). The discrepancy between the concentration of drug required for efficacy in the animal models was attributed to low CNS penetration of CP-310,713. In view of the efficacy and the poor bioavailability, Pfizer terminated the project.

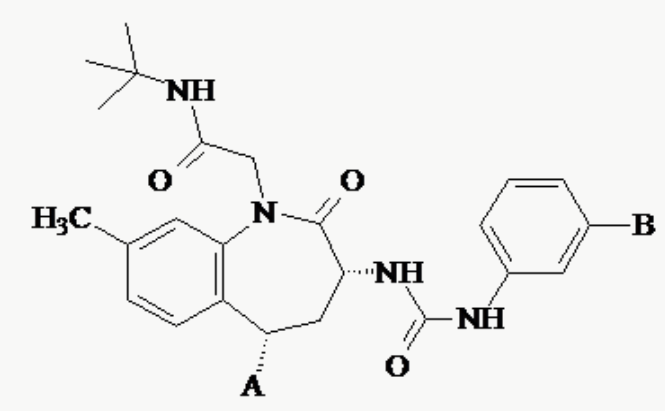

Figure 18: Structures of selected 3-ureido-1,4-benzazepine $\mathrm{CCK}_{\mathrm{B}} /$ gastrin receptor antagonists.

Table 3.

\begin{tabular}{|c|c|c|}
\hline Compound & A & B \\
\hline 7 & Phenyl- & $\mathrm{Cl}$ \\
\hline 8 & Cyclohexyl- & $\mathrm{CO} 2 \mathrm{H}$ \\
\hline
\end{tabular}

A series of potent CCKB antagonists based on the 1,5-benzodiazepin-2,4-dione skeleton possessing a C-3 ureido have been reported by Glaxo Wellcome [72-74] (Figure 19). Sterically large groups at N-1 are important for achieving high CCKB receptor affinity and good selectivity over the CCKA receptor, and 1-adamantylmethyl group was found to be optimal. The best compound of this series, GV150013X, showed affinity to CCKB at 7.5 $\mathrm{Nm}$ [75] and was selected for exploratory development in the treatment of panic attacks and anxiety. (Figure 19) Recently, the company Zeria Pharma Co. Ltd claimed a patent [76] on 3-phenylureido-1,4-benzodiazepine derivatives containing a cyclohexenyl ring, annulated to the heterocyclic seven membered ring. Information of the biological potential of the series has not yet been published (Figure 20 \& Table 4).

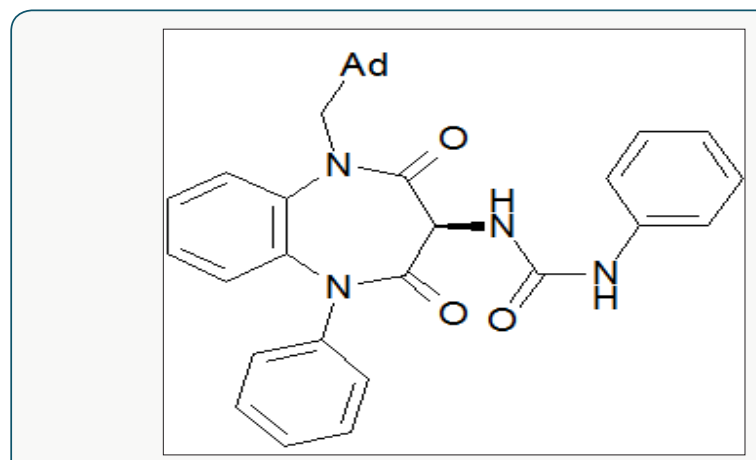

Figure 19: 1-Adamantyl-methyl-3-ureido-1,5-benzodiazepine derivative GV150013X.

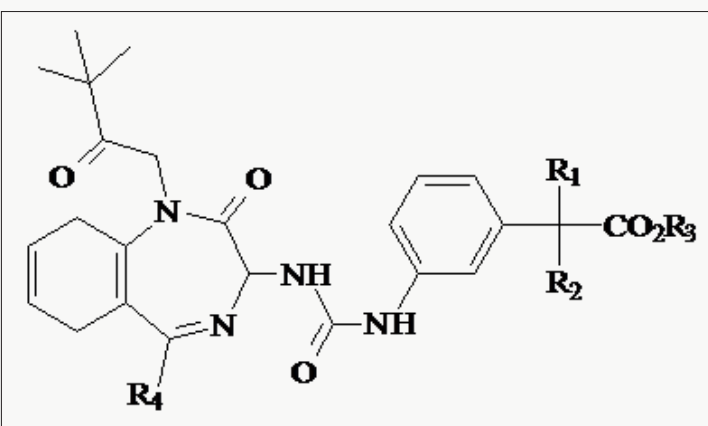

Figure 20: Structures of recently developed 3-ureido-1,4-benzodiazepine derivatives.

Table 4.

\begin{tabular}{|c|c|}
\hline $\mathrm{R}_{1}$ & Lower alkyl \\
\hline $\mathrm{R}_{2}, \mathrm{R}_{3}$ & $\mathrm{H}$ or lower alkyl \\
\hline $\mathrm{R}_{4}$ & Cyclohexyl or phenyl \\
\hline
\end{tabular}

\section{Quinazolinone-based Compounds}

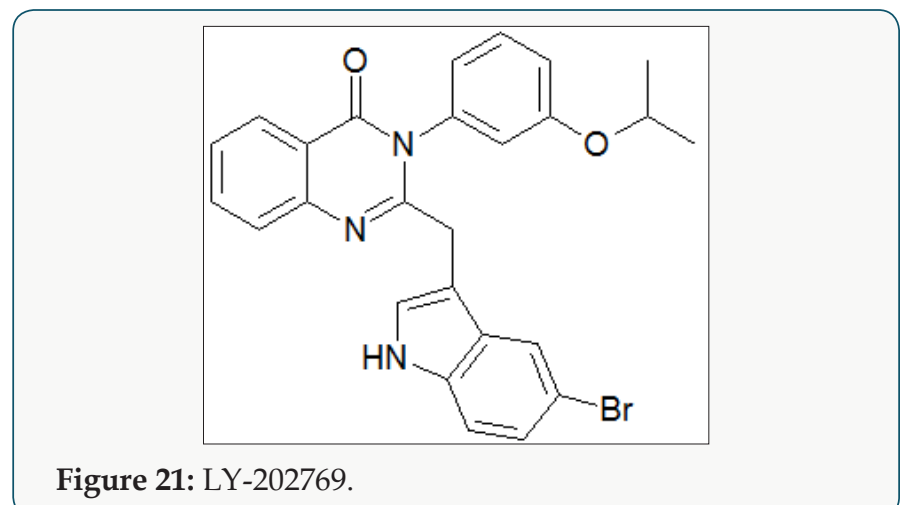

A quinazolino-1,4-benzodiazepin-5,13-dione also served at Eli Lilly [79] as starting point for the development of quinazolinonebased CCKB receptor antagonists. (Figure 21) LY-202769 potently inhibited [125I]-CCK-8(S) binding to the mouse cortical membrane 
(IC50 $=9.3 \mathrm{nM})$. Members of this series displayed up to a 20 -fold higher affinity for the CCKB receptors in cortical membranes over gastric tissues.

\section{Indol-2-based Compounds}

3,3-Disubstituted indol-2-ones, described by Chugai [78], inhibited [125I]-gastrin binding to guinea pig gastric glands and were selective over CCKA sites in pancreatic tissue. Only by replacing the geminal bisurea with a geminal acetamido-urea and through optimization of the substituent at N-1, AG-041R was yielded (Figure 22), which is orally active [79]. AG-041R inhibited specific binding of [125I]-gastrin binding to guinea pig gastric glands (IC50 $=1.11 \mathrm{nM}$ ), which was 500-fold greater than its affinity for CCKA receptors in the guinea pig pancreas. In the pylorus ligated rat, AG-041R inhibited pentagastrin stimulated acid secretion by IV administration (ID50 $=5 \mathrm{nmol} / \mathrm{kg}$ ) and had no inhibitory effect on carbachol or histamine stimulated secretion. The effect of intraduodenal administration of AG-041R on pentagastrin stimulated acid secretion has not been reported but it has been shown to inhibit basal acid secretion (ID50 = $10 \mu \mathrm{mol} /$ $\mathrm{kg}$ ) by this route, achieving prolonged duration (12 hrs at $10 \mathrm{mg} /$ $\mathrm{kg}$ po). AG-041R also exhibited greater potency than L-365,260 in water immersion stress ( 600 fold) and indomethacin-induced ulcer (6-fold) models.

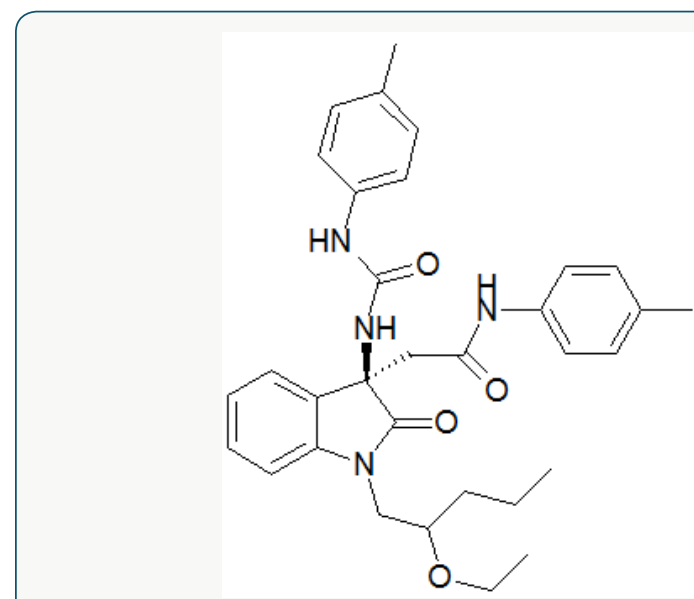

Figure 22: Structure of AG-041R.

\section{Recent Clinical Studies}

In an open study the cholecystokinin (CCK) receptor subtypes were characterized in medullary thyroid cancer by measuring the expression of CCK-A and CCK-B/gastrin receptor mRNA. Biopsy specimens were analyzed using reverse transcription polymerase chain reaction (RT-PCR). All 6 patients with medullary thyroid cancer had positive penta gastrin tests preoperatively. CCK-B/ gastrin receptors, but not CCK-A receptors were detected by RTPCR in all six biopsy specimens. By contrast, no CCK receptors were found in normal thyroid tissues or in other thyroid tumors (follicular adenoma, papillary carcinoma, or anaplastic carcinoma). It was concluded that the presence of CCK-B/gastrin receptors in medullary thyroid tumors may have important clinical implications [80].

\section{Potentiation of Clinical Effects}

It was reported that the cholecystokinin antagonist Proglumide potentiated morphine analgesia. The effect of Proglumide on spinal and supra spinal mu and spinal delta analgesia were investigated in mice in order to understand more fully the opiate receptor subtypes involved with this effect. It was found that Proglumide alone had no effect on tail flick latencies, but increased, in a dosedependent manner, tail flick latencies in morphine-tolerant mice. Proglumide also potentiated morphine analgesia in naive mice in a dose-dependent manner, with a maximal effect at 5-10 mg/kg. It both shifted the dose-response curve for morphine analgesia to the left and prolonged morphine's duration of action. Proglumide increased the sensitivity of supra spinal mu 1 receptor mechanisms of analgesia without influencing spinal mechanisms. Proglumide administered subcutaneously potentiated the analgesic actions of intracerebro ventricular [D-Ala2, MePhe4, Gly(ol)5] enkephalin (DAG0; (mu 1), but not intrathecal DAGO (mu 2) or [D-Pen2,D-Pen5] enkephalin (DPDPE; delta). The selective mu 1 receptor antagonist naloxonazine blocked proglumide-enhanced morphine analgesia [81]. As CCK receptors are present on pancreatic carcinoma cells it was determined whether either CCK itself or an antagonist of CCK could modulate the sensitivity of the human pancreatic cell line MIA-PaCa2 to cisplatin (DDP). The IC50 for a 1-h exposure to DDP was $35.3+/-3.2$ (SD) $\mu \mathrm{M}$. Exposure to CCK8 octapeptide at physiologic and supra-physiologic concentrations did not alter the sensitivity of MIA-PaCa2 cells to DDP. The CCK receptor antagonist MK-329 was directly cyto toxic to the MIA-PaCa2 cells on a constant exposure schedule with an IC50 of $9.5+/-1.4$ (SD) $\mu \mathrm{M}$. MK-329 enhanced the sensitivity of MIA-PaCa2 cells to DDP by a factor of 3.5 and the interaction between DDP and MK-329 was shown to be synergistic by median-effect analysis. At a level of $50 \%$ cell kill, the combination index was $0.58+/-0.10$. The ability of MK-329 to sensitize cells to DDP was schedule-dependent and required prolonged exposure to the antagonist following a 1-h exposure to DDP [82].

\section{Conclusion}

The most promising results in the cancer area are based on the non-potent and non-selective CCK antagonists Lorglumide and Proglumide. These early CCK antagonist occur a lack of potency and subtype receptor selectivity. Later work lead by Merck was focused on benzodiazepines and all clinical trials failed due to a very poor bioavailability. No clinical trials have been carried out with the second generation of Merck's water soluble ureas neither as a CNS drug nor as an anti-cancer agent. Various other major pharmaceutical companies designed and tested urea's, known for their use in analytical chemistry to form insoluble precipitates, which were very close to Merck's original structure. It can be 
expected that "really" novel compounds not belonging to the class of benzodiazepines or ureas will be identified in combinatorial libraries with a great potential impact in cancer research. Remarkable are the ongoing findings in which the concomitant administration of CCK antagonists enhanced the desired effects of other pharmaceuticals.

\section{References}

1. Guo YS, Townsend CM (2000) Roles of gastrointestinal hormones in pancreatic cancer. J Hepatobiliary Pancreat Surg 7: 276-285.

2. H Mineo H, Iwaki N, Kogishi K, Zabielski R, Onaga T, et al. (1995) Effects of intravenous infusions of cholecystokinin (CCK)-8 on exocrine and endocrine pancreatic secretion in conscious sheep. Comparative Biochemistry and Physiology Part A, Physiology 111(1): 133-138.

3. Ivy AC, Goldberg, EA (1928) The Discovery of a substance released from the upper intestine and produced gallbladder contractions. Am J Physiol 86: 599-606.

4. Mutt J, Jorpes JE (1971) Hormonal polypeptides of the upper intestine. Biochem J 125(3): 57-58.

5. Horwell DC, Beeby A, Clark CR, Hughes J (1987) Synthesis and binding affinities of cholecystokinin-(30-33) as probes for central nervous system cholecystokinin receptors. J Med Chem 30(4): 729-732.

6. Eysselein VE, Reeve JR, Eberlein G (1986) Cholecystokinin gene structure and molecular forms in tissue and blood. Gastroenterology 24(10): 645-659.

7. Böhme GA, Blanchard JC (1992) Cholecystokinins and their receptors. Functional aspects. Therapie 47(6): 541-548.

8. Lattmann E, Singh H (2000) Small organic molecules as cholecystokinin antagonists. J Sc (KKU) 28: 288-299

9. Lin CW, Shiosaki K, Miller TR, Witte DG, Bianchi BR, et al. (1991) Characterization of two novel cholecystokinin tetra peptide (3033) analogues, A-71623 and A-70874, that exhibit high potency and selectivity for cholecystokinin-A receptors. Mol Pharmacol 39(3): 346351.

10. Noble F, Roques BP (1999) CCK-B receptor: Chemistry, molecular biology, biochemistry and pharmacology. Progress in Neurobiology 58(4): 349-379.

11. Clark CR, Dauni P, Hughes J (1986) A study of the cerebral cortex cholecystokinin receptor using two radiolabelled probes: Evidence for a common CCK 8 and CCK 4 cholecystokinin receptor binding Site. J Neurochem 46(4): 1094-1101.

12. Takeda Y, Hoshino M, Yanaihara N, Yanaihara C, Isobe J (1989) Comparison of CCK-8 receptors in the pancreas and brain of rats using CCK-8 analogues. Jpn J Pharmacol 49(4): 471-481.

13. Dirieux C, Pelaprat D, Charpentier B, Morgat JL, Roqucs BP (1988) Characterization of $[3 \mathrm{H}] \mathrm{CCK}$ binding sites in mouse and rat brain. Neuropeptides 12(3): 141-148.

14. Saito A, Goldfine ID, Williams JA (1981) Characterization of receptors forcholecystokinin and related peptides in mouse cerebral cortex. J Neurochem 37(2): 483-490.

15. Hirata M, Tsuchida A, Iwao T, Sasaki T, Matsubara K, et al. (1999) Cholecystokinin regulates the invasiveness of human pancreatic cancer cell lines via protein kinase C pathway. Int J Oncol 14(6): 1129-1135.

16. Mandair KK, Towner P, Stamford IF, Morris JD, Harper E, et al. (1998) Cholecystokinin receptors in human pancreatic cancer cell lines. Eur J Cancer 34(9): 1455-1459.
17. Imdahl A, Eggstein S, Crone C, Farthmann EH (1989) Growth of colorectal carcinoma cells: regulation in vitro by gastrin, pentagastrin and the gastrin-receptor antagonist proglumide. J Cancer Res Clin Oncol 115(4): 388-392.

18. Hudd C, LaRegina MC, Devine JE, Palmer DC, Herbold DR, et al. (1989) Response to exogenous cholecystokinin of six human gastrointestinal cancers xenografted in nude mice. Am J Surg 157(4): 386-394.

19.Vidal Y, Plana RR, Cifarelli A, Bizzarri D (1980) Effects of antigastrin drugs on the interaction of ${ }^{125} \mathrm{I}$-human gastrin with rat gastric mucosa membranes. Hepata-Gastroenterol 27(1): 41-47.

20. Stening GF, Grossman MI (1969) Gastrin-related peptides as stimulant of pancreatic and gastric secretion. Amer J Physiol 217: 262-266.

21. Jensen RT, Zhou ZC, Murphy RB, Jones SW, Setnikar I (1986) Structural features of various proglumide-related cholecystokinin receptor antagonists. Am J Physiol 251(6 Pt 1): G839-G846.

22. Makovec F, Bani M, Chiste R, Revel L, Rovati LC (1986) Differentiation of central and peripheral cholecystokinin receptors by new glutaramic acid derivatives and cholecystokinin-antagonistic activity. Arzmeim Forsch 36(1): 98-102.

23. Wakatsuki K, Saito T, Saeki M, Ninomiya K, Kasai H, et al. (1997) Cholecystokinin antagonistic activities of loxiglumide. Arzneim Forsch 47(10): 1130-1133.

24. Hirata M, Itoh M, Tsuchida A, Ooishi H, Hanada K, et al. (1996) Cholecystokinin receptor antagonist, loxiglumide, inhibits invasiveness of human pancreatic cancer cell lines. FEBS Lett 383(3): 241-244.

25. Shimazoe T, Funakoshi A, Kono A (1992) [Effects of UFT and loxiglumide (CR1505) on liver metastasis of human pancreatic cancer cell line, KP-1 $\mathrm{N}$ in nude mice]. Gan To Kagaku Ryoho 19(9): 1321-1325.

26. Watson SA, Morris DL, Durrant LG, Robertson JF, Hardcastle JD (1992) Inhibition of gastrin-stimulated growth of gastrointestinal tumour cells by octreotide and the gastrin/cholecystokinin receptor antagonists, proglumide and lorglumide. Eur J Cancer 28A(8-9): 1462-1467.

27. Nio Y, Tsubono M, Morimoto H, Kawabata K, Masai Y, et al. (1993) Loxiglumide (CR1505), a cholecystokinin antagonist, specifically inhibits the growth of human pancreatic cancer lines xenografted into nude mice. Cancer 72(12): 599-606.

28. Singh P, Le S, Beauchamp RD, Townsend CM, Thompson JC (1987) Inhibition of pentagastrin-stimulated up-regulation of gastrin receptors and growth of mouse colon tumor in vivo by proglumide, a gastrin receptor antagonist. Cancer Res 47(19): 5000-5004.

29. Morimoto H, Nio Y, Tsubono M, Tseng CC, Kawabata K, et al. (1993) Inhibitory effects of a cholecystokinin antagonist, loxiglumide (CR1505), on the growth of freshly separated and xenografted human pancreatic cancer. J Surg Oncol 53(1): 47-53.

30. Militello C, Sperti C, Di Prima F, Pedrazzoli S (1997) Clinical evaluation and safety of loxiglumide (CCK-A receptor antagonist) in nonresectable pancreatic cancer patients. Italian Pancreatic Cancer Study Group. Pancreas 14(3): 222-228.

31. Peikin SR, Costenbader CL, Gardner JD (1979) Actions of derivatives of cyclic nucleotides on dispersed acini from guinea pig pancreas. J Biol Chem 254(12): 5321-5327.

32. Boden PR, Higginbottom M, Hill DR, Horwell DC, Hughes J, et al. (1993) Cholecystokinin dipeptoid antagonists: Design, synthesis and anxiolytic profile of some novel CCK-A and CCK-B and mixed CCK-A/CCK-B antagonists. J Med Chem 36(5): 552-565.

33. Kerwin JF, Wagenaar F, Kopecka H, Lin W, Miller T (1991) Cholecystokinin antagonists: (R)-Tryptophan-based hybrid antagonists of high affinity and selectivity for CCK-A receptors. J Med Chem 34(12): 3350-3359. 
34. Romani R, Howes LG, Morris DL (1996) Gastrin receptor antagonist CI988 inhibits growth of human colon cancer in vivo and in vitro. Aust N Z J Surg 66(4): 235-237.

35. Romani R, Howes LG, Morris DL (1996) Dose dependent in vivo inhibition of human colorectal cancer (LoVo) by the gastrin receptor antagonist, CI-988. Clin Exp Pharmacol Physiol 23(5): 438-440.

36. Clark CR, Dauni P, Hughes J (1986) A study of the cerebral cortex cholecystokinin receptor using two radiolabelled probes: Evidence for a common $\mathrm{CCK}_{8}$ and $\mathrm{CCK}_{4}$ cholecystokinin receptor binding Site. J Neurochem 46(4): 1094-1101.

37. Stark HA, Sharp CM, Sutliff VE, Martinez J, Jensen RT (1989) CCKJMV-180: a peptide that distinguishes high affinity cholecystokinin receptors from low affinity cholecystokinin receptors. Biochem Biophys Acta 1010(2): 145-150.

38. Rasmussen K, Czachura JF, Stockton ME, Howbert JJ (1993) Electrophysiological effects of diphenylpyrazolidinone cholecystokinin-B and cholecystokinin-A antagonists on midbrain dopamine neurons. J Pharmacol Exp Ther 264(1): 480-488.

39. Howbert JJ, Lobb KL, Britton TC, Mason NR, Bruns RF (1993) Diphenylpyrazolidinone and benzodiazepine cholecystokinin antagonists: A case of convergent evolution in medicinal chemistry. Bioorg Med Chem Lett 3(5): 875-880.

40. Rasmussen K, Stockton ME, Czachura JF, Howbert JJ (1995) Cholecystokinin and schizophrenia: The selective CCK-B antagonist decreases midbrain dopamine unit activity. Expert Opin Invest Drugs 4: 313-322.

\section{1. (1991) Patent: Rhone-Poulenc, WO 113874}

42. Takeda Y, Kawagoe K, Yokomizo A, Yokomizo Y, Hosokami T et al. (1998) Synthesis of phenoxyacetic acid derivatives as highly potent antagonists of gastrin/ cholecystokinin-B receptors. Chem Pharm Bull 46(3): 434444.

43. Hagishita S, Murakami Y, Seno K, Kamata S, Haga N (1997) Ureidomethylcarbamoyl-phenylketones as selective $\mathrm{CCK}_{\mathrm{B}}$ receptor antagonists. Bioorg Med Chem 5: 1695-1714.

44. Kalindjian SB, Harper EA, Pether MJ (1995) The synthesis of a radioligand with high potency and selectivity for CCK-B/gastrin receptors. J Med Chem 38: 4294-4302.

45. (2001) Patent James Black FDN, 2000, WO 2000027823 see McDonald IM CCK2 receptor antagonists. Exp Opin Ther Patents 11: 445-462.

46. Sugaya K, Matsuda I, Uruna T, Kubota K (1984) Studies on the CCK antagonism by benzodiazepines: Displacement of CCK by benzodiazepines in the binding in mouse brain CCK receptor. Jpn J Pharmacol 40: 114p.

47. Kubota K, Sugaya K, Koizumi Y, Toda M (1989) Cholecystokinin antagonism by anthramycin, a benzodiazepine antibiotic, in the central nervous system in mice. Brain Res 485: 62-66.

48. Bock MG, DiPardo RM, Rittle KE, et al. (1986) Cholecystokinin antagonists. Synthesis of asperlicin analogues with improved potency and water solubility. J Med Chem 29(10): 1941-1952.

49. Hosontanti R, Chowdhury P, McKay D, Rayford PL (1988) Effect of L-364718, a new CCK antagonist, on amylase scretion in isolated rat pancreatic acini. Pancreas 3(1): 95-98.

50. Anderson L, Dockray GL (1988) The cholecystokinin antagonist L-364,718 inhibits the action of cholecystokinin but not bombesin on rat pancreatic secretion in vivo. Euro J Pharmacol 146(2-3): 307-311.

51. Silver AJ, Flood JF, Song AM, Morley JE (1989) Evidence for a physiological role for CCK in the regulation of food intake in mice. Am J Physiol 256: 646-652.
52. Dunlop J (1998) CCK receptor antagonists. Gen Pharmacol 31(4): 519 524.

53. Hill DR, Shaw , Graham W, Woodruff GN (1990) Autoradiographical detection of cholecystokinin-A receptors in primate brain using $125 \mathrm{I}$ bolton Hunter CCK-8 and 3H-MK-329. J Neurosci 10(4): 1070-1081.

54. Forgue Lafitte ME, Coudray AM, Aubert JP, Gespach C, Bara J (1996) Devazepide (L-364718) inhibits growth and increases expression of tumor markers in HT29-S-B6 cells. Acad Sci III 319(12): 1133-1138.

55. Abbruzzese JL, Gholson CF, Daugherty K, Larson E, DuBrow R, et al. (1992) A pilot clinical trial of the cholecystokinin receptor antagonist MK-329 in patients with advanced pancreatic cancer. Pancreas 7(2): 165-171.

56. Evans BE, Rittle KE, Bock MG, DiPardo RM, Freidinger RM, et al. (1986) Design of potent, orally effective, non peptidal antagonists of the peptide hormone cholecystokinin. Proc Natl Acad Sci, USA 83(13): 4918-4922.

57. Bock MG, DiPardo RM, Evans BE (1989) Benzodiazepine gastrin and brain cholecystokinin receptor ligands. L-365,260. J Med Chem 32(1): $13-24$.

58. Dourish CT, Rycroft W, Iversen SD (1989) Postponement of satiety by blockade of brain cholecystokinin-B receptors. Science 245(4925): 1509-1511.

59. Haradahira T, Inoue O, Kobayashi K, Suzuki K (1998) Synthesis and evaluation of 11C-labeled nonpeptide antagonists for cholecystokinin receptors: [11C] L-365,260 and L-365,346. Nucl Med Biol 25(3): 203208.

60. Ohlsson B, Fredaong N, Axelson J (1999) The effect of bombesin, cholecystokinin, gastrin, and their antagonists on proliferation of pancreatic cancer cell lines. Scand J Gastroenterol 34(12): 1224-1229.

61. Thumwood CM, Hong J, Baldwin GS (1991) Inhibition of cell proliferation by the cholecystokinin antagonist L-364,718. Exp Cell Res 192(1): 189192.

62. Chamber MS, Hobbs SC, Flecher SR, Matassa VG, Mitchell PJ, et al. (1993) L-708,474: The C5-cyclohexyl analogue of L-365,260, a selective high affinity ligand for the CCK-B/gastrin receptor. Bioorg Med Chem Lett 3(10): 1919-1924.

63. Showell GA, Bourrain S, Neduvelil JG, Fletcher AE, Baker R, et al. (1994) High affinity and potent, water soluble 5-amino-1,4-benzodiazepine $\mathrm{CCK}_{\mathrm{B}}$ /gastrin receptor antagonists containing a cationic solubilising group. J Med Chem 37(6): 719-721.

64. Castro LC, Broughton HB, Russell MGN, Rathbone R, Watt AP (1997) 5-(Piperidin-2-yl)- and 5-(homopiperidin-2-yl)-1,4-benzodiazepines: High-affinity, basic ligands for the cholecystokinin-B receptor. J Med Chem40(16): 2491-2501.

65. Bock MG, DiPardo RM, Mellin EC, Newton NC (1994) Second-generation benzodiazepine CCK-B antagonists. Development of sub nano molar analogues with selectivity and water solubility. J Med Chem 37(6): 722724 .

66. Semple G, Ryder H, Kendrick DA, Szelke M, Ohta M, et al. (1997)(3R)$\mathrm{N}$ (tert-butylcarbonylmethyl)-2,3-dihydro-2-oxo-5-(2-pyridyl)-1H1,4-benzodiazepin-3-yl)-N'-(3-(methylamino)phenyl)urea (YF476): A potent and orally active gastrin/CCK-B antagonist. J Med Chem 40(3): 331-341.

67. Yuji S, Hidenori Y, Yumiko H, Akito N, Keito M, et al. (1994) Characterisation of YM022: its $\mathrm{CCK}_{\mathrm{B}}$ /gastrin receptor binding profile and antagonism to CCK-8-induced $\mathrm{Ca}^{2+}$ mobilization. Eu J Pharm Mol Pharm Sec 269(2): 249-254.

68. Semple G, Ryder H, Kendrick DA, Szelke M, Ohta M, et al. (1996) Synthesis and biological activity of 1-alkylcarbonylmethyl analogues of YM022. Bioorg Med Chem Lett 6(1): 51-54. 
69. Masato S, Yutaka K, Yoshinori O, Akito N, Keiji M, et al. (1995) New 1,4-benzodiazepin-2-one derivatives as gastrin/cholecystokinin-B antagonists. Chem Pharm Bull 43(12): 2159-2167.

70. Murayama T, Matsumori Y, Iwata N, Ito M, Taniguchi T, et al. (1996) Antiproliferative effect of a novel cholecystokinin-B/gastrin receptor antagonist, YM022. Jpn J Cancer Res 87(7): 743-750.

71. Padia JK, Chilvers H, Daum P, Pinnock R, Suman Chauhan N, et al.(1997), Design and synthesis of novel non-peptides CCK-B receptor antagonists. Bioorg Med Chem Lett 7: 805-810.

72. Finizia G, Donati D, Oliosi B, Tranquillini ME, Ursini A (1996) Synthesis and evaluation of novel 1,5-benzodiazepines as potent and selective CCK-B ligands. Effect of the substitution of the N-5 phenyl with alkyl groups. Bioorg Med Chem Lett 6(24): 2957-2962.

73. Wilson TM, Henke BR, Momtahen TM, Myers PL, Sugg EE, et al. (1996) 3-[2-(N-Phenylacetamide)]-1,5-benzodiazepines: Orally active, binding selective CCK-A agonists. J Med Chem 39(15): 3030-3034

74. Bailey N, Box PC, Car RAE, Cooke JWB, Evans B, et al. (1997) Nove 1,5-benzodiazepindione gastrin/ $\mathrm{CCK}_{\mathrm{B}}$ antagonists. Bioorg Med Chem Lett 7(3): 281-286.

75. Hirst GC, Aquino C, Birkemo L, Croom GK, Dezube M, et al. (1996) Discovery of 1,5-benzodiazepines with peripheral cholecystokinin
(CCK-A) receptor agonist activity (II): Optimization of the C3 amino substituent. J Med Chem 39(26): 5236-5245.

76. (2000) PCT-WO 9964403 Int Cl C 07 D-243/12. Zeria Pharma Co. Ltd, Saitama (JP), India.

77. McDonald IM (2001) CCK $_{2}$ receptor antagonists. Exp Opin Ther Patents 11: 445-462.

78. (1994) Chugai Pharmaceutical Co. Ltd, Japan.

79. Esaki T, Emura T, Tachibani K (1996) Chiral indolone acetamides: A new class of orally active CCK-B/gastrin antagonists. $14^{\text {th }}$ Symposium of Medicinal Chemistry. Maastricht, p. 304.

80. Amiri Mosavi A, Ahlman H, Tisell LE, Waengberg B, Kaelby L, et al. (1999) Expression of cholecystokinin-B/gastrin receptors in medullary thyroid cancer. Eur J Surg 165(7): 628-631.

81. Bodnar RJ, Paul D, Pasternak GW (1990) Proglumide selectively potentiates supraspinal mu 1 opioid analgesia in mice. Neuropharmacol 29(5): 507-510.

82. Jamshidipour R, Pinho EB, Hom DK, Howell SB (1994) Enhancement of the cytotoxicity of cisplatin by the cholecystokinin antagonist MK-329 in a human pancreatic cancer cell line. Cancer Chemother Pharmacol 34(6): 484-490. (c) This work is licensed under Creative

Submission Link:

DOI: 10.32474/DDIPIJ.2018.01.000106

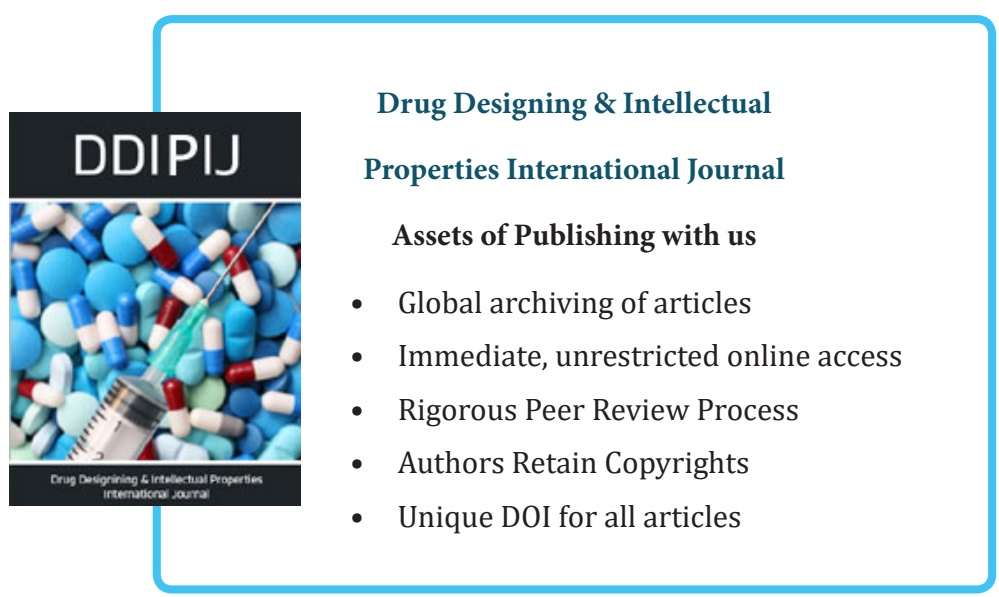

